\title{
O REFLEXO DAS DESIGUALDADES MATERIAIS E SIMBÓLICAS NO DISCURSO SOBRE A TITULAÇÃO DE TERRITÓRIOS QUILOMBOLAS
}

(The reflection of the material and symbolic inequalities in the discourse about the demarcation of quilombolas territories)

\author{
Micheline Mattedi Tomazi ${ }^{1}$ \\ Universidade Federal do Espírito Santo \\ Girley Vieira da Silva ${ }^{2}$ \\ Universidade Federal do Espírito Santo
}

\begin{abstract}
RESUMO
No Brasil, o racismo em desfavor das minorias étnico-raciais é um problema social que se materializa em desigualdades tanto materiais quanto simbólicas. Como o discurso e a comunicação são fundamentais para a criação e a manutenção de modelos mentais racistas presentes nas interações do dia a dia, este artigo tem por objetivo examinar as estruturas discursivas presentes em uma reportagem publicada no jornal A Gazeta sobre a titulação de territórios quilombolas. E tendo como suporte teórico-metodológico a Análise Crítica do Discurso de base sociocognitiva, o artigo identificou tratamento desfavorável e preconceituoso dado aos quilombolas no objeto analisado.
\end{abstract}

Palavras-chave: Análise Crítica do Discurso. Racismo. Quilombolas. Imprensa.

\begin{abstract}
In Brazil, the racism against ethnic and racial minorities is a social problem that materializes in inequalities both as symbolic and materials. As the speech and communication are central to the creation and maintenance of mental models racists present in nowadays interactions, this paper examines article published in A Gazeta about the demarcation of quilombolas territories. And using the critical discourse analysis as a theorical and methodological support, we identify a unfavourable and biased approach given to the Quilombolas in the Newspaper's discourse.
\end{abstract}

Keywords: Critical discourse analysis. Racismo. Quilombolas. Press.

\section{RESUMEN}

En Brasil, el racismo en contra de las minorías étnico-raciales es un problema social que se materializa en desigualdades tanto materiales como simbólicas. Como el discurso y la comunicación son fundamentales para la creación y el mantenimiento de modelos mentales racistas presentes en las interacciones del día a día, este artículo examina el reportaje publicado en el diario A Gazeta sobre la titulación de territorios quilombolas. Y teniendo como soporte teórico-metodológico el Análisis Crítico del Discurso de base sociocognitiva, el artículo identificó un trato desfavorable y preconceptuoso dado a los quilombolas en el objeto analizado.

Palavras clave: Análisis Crítico del Discurso. Racismo. Cimarrones. Prensa.

\footnotetext{
${ }^{1}$ Professora Associada do Departamento de Línguas e Letras e do Programa de Pós-Graduação em Linguística da Universidade Federal do Espírito Santo (PPGEL/UFES). Coordenadora do Grupo de Estudos sobre Discursos da Mídia (Gedim/UFES/CNPq). Contato: michelinetomazi@gmail.com.

${ }^{2}$ Servidor Público Federal de Carreira da Área de Comunicação Social. Doutorando em Estudos Linguísticos pela Universidade Federal do Espírito Santo (PPGEL/UFES) e pesquisador do Grupo de Estudos sobre o Discurso da Mídia (Gedim/UFES/CNPq) e do Grupo de Pesquisa Educação para as Relações Étnico-Raciais, Territorialidades e Novas Mídias (Neab/UFES/CNPq). Contato: girleyvs@gmail.com.
} 
Recebido em: setembro 2019

Aceito em: dezembro 2019

DOI: $\underline{10.26512 / \text { les.v20i2.27146 }}$

\section{INTRODUÇÃO}

É fato que no Brasil, a exemplo de outros países da América Latina, o racismo contra grupos minoritários é um problema social estruturante (VAN DIJK, 2008). São diversos estudos e pesquisas que demonstram as disparidades no acesso a bens materiais e simbólicos entre os diferentes grupos.

Quando observados os dados relativos especificamente aos afrodescendentes, o cenário é repulsivo. A população negra é a que mais sofre com a violência (IPEA, Atlas da Violência no Brasil, 2017), é a mais afetada pelo desemprego e pelo preconceito no mercado de trabalho (ETHOS, 2016), é aquela que possui a menor renda (OXFAM, 2017) e que tem menos acesso à educação (IBGE, 2017), além de também ser preterida em termos de representatividade cultural e política no cenário nacional. Nesse contexto, as estatísticas apresentam aspectos que comprovam o racismo estrutural vigente neste país.

Embora essas estatísticas sejam mais que suficientes para mobilizar ações que visem a uma mudança na lógica de supremacia racial, outro aspecto também enseja [re]ação: a negação do racismo no Brasil. E é para colaborar com essas demandas, instigados por um dos principais pressupostos da Análise Crítica do Discurso (doravante denominada ACD) - o de que os analistas críticos devem desafiar a desigualdade social (VAN DIJK, 2016a) -, que selecionamos como objeto de análise para este artigo uma publicação da imprensa capixaba sobre as comunidades remanescentes de quilombos - minoria étnico-racial cuja história é intrinsecamente relacionada ao processo de escravização e seus complexos desdobramentos.

Partindo da premissa de que o discurso e a comunicação são cruciais no estabelecimento e na reprodução do poder e das desigualdades materializadas sob a forma de fenômenos como o racismo (VAN DIJK, 1994), este artigo tem por objetivo geral analisar linguístico-discursivamente uma reportagem veiculada no jornal A Gazeta, em 27 de maio de 2007, sobre a titulação de territórios quilombolas, a fim de demonstrar como o preconceito e as ideologias racistas são discursivamente construídas e sustentadas pelas relações de poder. A fim de chegarmos ao objetivo pretendido para este artigo, partimos da abordagem sociocognitiva da ACD, de van Dijk (1994, 2000, 2008, 2015a, 2015b, 2016a, 2016b, 2017a e 2017b), em diálogo com estudos sobre o racismo do próprio van Dijk $(2000,2008)$ e de trabalhos de outros pesquisadores que se debruçaram sobre 
esse tema (FERNANDES, 2015; MUNANGA, 2005), sobre as comunidades quilombolas (ARRUTI, 1997; OLIVEIRA, 2016) e sobre a imprensa (CASTELLS, 2015; TRAQUINA, 2005).

Dentre as estruturas e estratégias discursivas relevantes que poderiam ser investigadas no texto selecionado [e são muitas possíveis], escolhemos realizar uma análise do tipo qualiinterpretativa a partir das seguintes categorias: semântica global e, consequentemente, das demais estruturas discursivas que de alguma forma atuaram para a conformação da primeira, como a seleção lexical e a sintaxe oracional; estruturas de contexto; e quadrado ideológico da polarização.

A análise das estruturas discursivas, sob o ponto de vista sociocognitivo da ACD, dá-nos condições de desvelar os sentidos mais gerais do texto que costumam ser armazenados na memória dos leitores (VAN DIJK, 2016b) e a identificar valores, atitudes, opiniões, propósitos etc. do ator social que produziu o discurso (VAN DIJK, 2017b). Isso só é possível porque essa abordagem da ACD leva em consideração a inter-relação entre discurso, sociedade e cognição.

Importante ressaltar que a seleção do objeto $^{3}$ de estudo se pautou em dois critérios principais: o temporal, pois o ano de 2007 apresenta um número importante de publicações do jornal sobre o tema estudado; e o textual-discursivo, considerando as especificidades da reportagem como um gênero jornalístico que se diferencia dos demais justamente pelo aprofundamento nos temas abordados (MARQUES DE MELO, 2003).

Para atingir os objetivos pretendidos, além da parte introdutória, este artigo foi organizado em cinco seções: na primeira, apresentamos conceitos da ACD que dão o suporte teórico-analítico para a investigação do abuso de poder e do racismo no discurso em questão; na segunda, exploramos concepções relacionadas ao racismo e discorremos sobre o contexto que envolve essa prática no Brasil; na terceira, traçamos um panorama sobre a questão quilombola e o direito ao território; na quarta, abordamos aspectos importantes sobre o poder da comunicação e o discurso jornalístico; e, na quinta, promovemos a análise da reportagem selecionada, seguida de nossas considerações finais.

\section{ABORDAGEM SOCIOCOGNITIVA E CRÍTICA DO DISCURSO}

A abordagem sociocognitiva - perspectiva da ACD empregada neste artigo - é multidisciplinar e utiliza como base material de análise elementos de duas dimensões: do macronível, que é estruturado pelo uso da linguagem - o discurso, a interação verbal e a

\footnotetext{
${ }^{3}$ Levantamento realizado nos arquivos do jornal A Gazeta identificou a ocorrência de 49 textos veiculados sobre titulação de territórios quilombolas entre 1988 (ano da promulgação da CF) e 2017, sendo que o ano de 2007 concentrou $45 \%$ das ocorrências ao longo de 29 anos pequisados. As ocorrências estão assim distribuídas: 19881997[0]; 1998[1]; 1999-2002[0]; 2003[1]; 2004[7]; 2005-2006[0]; 2007[22]; 2008[3]; 2009[3]; 2010[2]; 2011[0]; 2012[1]; 2013[6]; 2014[2]; 2015[1]; 2016-2017[0].
} 
comunicação -; e do micronível, constituído a partir da ordem social - o poder, a dominação e a desigualdade entre grupos sociais (VAN DIJK, 2016a).

Entendido como um fenômeno complexo, nessa perspectiva da ACD, o conceito de discurso pode ser aplicado

[...] para qualquer forma de língua manifestada como texto (escrito) ou fala-emintenção (falado), num sentido semiótico amplo. Isso inclui as estruturas visuais, como o layout, os tipos de letras e imagens para textos escritos ou impressos, e os gestos, a expressão facial e outros signos semióticos para a interação falada. Esse conceito de discurso pode incluir combinações de material sonoro e visual em muitos discursos multimodais híbridos, caso dos filmes, da televisão, dos telefones celulares, da internet e de outros canais e veículos de comunicação (VAN DIJK, 2017b, p. 166).

Portanto, além do tratamento multidisciplinar que deve ser dado ao objeto, também é central para esse tipo de estudo a compreensão de que a relação entre o discurso e a sociedade é inextricavelmente mediada pela cognição: “[...] não existem ligações diretas entre estruturas sociais e estruturas discursivas, pois toda produção, compreensão e usos do discurso são mediados por representações mentais dos participantes" (VAN DIJK, 2016b, p. 20).

Dessa forma, uma análise que emprega a abordagem sociocognitiva do discurso deve dar conta de relacionar estruturas discursivas (semântica local, global, signos multimodais, sintaxe, superestruturas, estruturas retóricas, pragmáticas e conversacionais etc.), estruturas cognitivas (crenças, conhecimento, experiências individuais, atitudes, ideologias) e estruturas sociais (cultura, história, raça, etnia, gênero, classe social, instituições, Estado etc.) de forma sistêmica (TOMAZI; CABRAL, 2017, p. 52).

Com base nesse pressuposto, e em virtude deste trabalho utilizar algumas estruturas do discurso para a exploração do objeto, torna-se importante delimitar como cada uma delas pode colaborar nesta análise. Nesse sentido, em termos de sintaxe oracional, entendemos que mais do que compreender a função dos termos nas orações, é preciso realçar como construções sintáticosemânticas também carregam posicionamentos. Conforme descreve van Dijk (2017b, p. 230): "Muitas variantes sintáticas têm uma pluralidade de significados ou funções diferentes e, portanto, precisam ser explicadas em termos semânticos, pragmáticos ou retóricos”.

Da mesma forma, as palavras empregadas pelos atores sociais na construção do sentido (seleção lexical) têm implicações sociais e políticas. Pela análise do léxico é possível mapear valores, crenças, ideologias etc. porque: "Em suma, poucas categorias contextuais não são de modo algum marcadas pela escolha do léxico, em acréscimo à escolha das expressões dêiticas, das partículas de discurso e de outros tipos de palavras [...]" (VAN DIJK, 2017b, p. 238). 
A observação dessas estruturas ou estratégias do discurso (sintaxe oracional e seleção lexical) ajudarão a compreender o papel de outra estrutura na composição do discurso analisado: o da Semântica Global. Também chamada de "Significado Global do Discurso" (VAN DIJK, 2017a, p. 137), essa estrutura representa a matriz geral de significação e, por esse aspecto, reúne atributos capazes de influenciar de forma mais direta os modelos mentais, que consistem em conjuntos de conhecimentos socioculturalmente determinados e adquiridos a partir da nossa experiência pessoal e social.

Essa categoria pode ser observada a partir da presença de macroposições semânticas - “[...] aqueles sentidos gerais mais lembrados pelos leitores" (VAN DIJK, 2016b, p. 23). E a composição dos gêneros jornalísticos ajuda a evidenciar os principais sentidos do discurso do jornal (os tópicos e temas principais), pois eles são destacados a partir do uso de títulos, subtítulos, chapéus, legendas, linha fina etc.

Além de analisar as estruturas do discurso, relacionando-as com as estruturas sociais e cognitivas, van Dijk (2016b) recomenda que as estruturas de contexto também sejam examinadas, pois representam parâmetros relevantes da situação comunicativa e influenciam diretamente na forma como cada ator social, tendo como base seus modelos de contexto, vai construir os discursos. São esses parâmetros que podem interferir também na forma como o ator social fará as adequações da estrutura e do conteúdo em cada situação comunicativa específica.

Em termos de estratégia discursiva, nesta análise pretendemos observar como o jornal posicionou e caracterizou os atores sociais no discurso, pois indicará o emprego do quadrado ideológico. Esse artifício se dá por meio da oposição entre "[...] grupos básicos das ideologias subjacentes: enfatizando nossas coisas boas, enfatizando suas coisas ruins, mitigando nossas coisas ruins e mitigando suas coisas boas [...]" (VAN DIJK, 2016a, p. 29).

Outrossim, a ACD também dá relevância ao conceito de ideologia por representar um sistema de ideias que possuem propriedades sociocognitivas e sociais capazes de determinar atitudes de grupos em relação a determinados aspectos da vida social. Como uma espécie de núcleo cognitivo da coletividade social (VAN DIJK, 2015b), as ideologias existem como crenças que são refletidas em representações mentais.

E sendo o racismo um recurso ou uma “[...] arma ideológica para legitimar e justificar a dominação de uns sobre os outros [...]” (MUNANGA, 2005, p.18), a reprodução e a disseminação do racismo também ocorre por meio de interações que contribuem para a formação de modelos mentais a partir dos quais os indivíduos passam a representar, a orientar suas atitudes e seus pensamentos e a [re]produzir discursos sobre os negros e minorias étnico-raciais. Conforme 
esclarece van Dijk (2008, p. 15), “[...] o racismo não é inato, mas aprendido [...] devido às formas de texto e de fala numa ampla variedade de eventos comunicativos".

Assim, com o objetivo de contextualizar a forma como o racismo no Brasil vem sendo construído e reproduzido a partir da promoção de ideologias racistas e de modelos mentais socialmente compartilhados, a próxima seção apresentará uma discussão baseada em teóricos que pesquisam as práticas racistas e suas implicações sociais.

\section{NÃO SOMOS RACISTAS!?}

“O racismo é uma prática diária e difundida. Ele é onipresente e forte” (MUNANGA, 2005, p. 49). Essas afirmações soariam atuais em qualquer momento da história do Brasil. Isso demonstra como o racismo tem, ao longo dos anos, sobrevivido e se materializado sob a forma de desigualdades em diferentes áreas, sendo esses efeitos negativos aprofundados quando estão envolvidas parcelas socialmente frágeis da população.

Van Dijk (2016b, p.18) explica que o racismo, como forma de dominação social, pode ser descrito a partir de duas dimensões principais, quais sejam: “[...] representações socialmente compartilhadas (atitudes preconceituosas) [...]" e "[...] práticas sociais específicas de tratamento ilegal (discriminação) [...]”.

O que fica evidente é que essa prática ocorre sob diferentes formas, umas mais explícitas e passíveis de punição e outras mais subjetivas, as quais costumam ser negadas por quem as pratica. Por isso, torna-se interessante delimitar qual o conceito de racismo - e sua abrangência - aplica-se a este artigo. Uma definição proposta pela Convenção da Organização das Nações Unidas (ONU/1966) sobre a Eliminação de todas as Formas de Discriminação Racial colabora com a delimitação conceitual e ainda demonstra que o racismo pode existir em situações que vão muito além de ofensas proferidas em função da cor da pele ou da origem étnica, por exemplo. Racismo, em sentido mais amplo, significa

[...] qualquer distinção, exclusão, restrição ou preferências baseadas em raça, cor, descendência ou origem nacional ou étnica, que tenha como objeto ou efeito anular ou restringir o reconhecimento, o gozo ou exercício, em condições de igualdade, os direitos humanos e liberdades fundamentais no domínio político, social ou cultural, ou em qualquer outro domínio da vida pública (ONU, 1966).

A história demostra que a ideologia racista que vigora nos dias de hoje no Brasil foi elaborada muito antes dos europeus desembarcarem por aqui. A invenção da supremacia branca na Europa do século XV teve como objetivo justificar as expansões econômicas e territoriais daquele continente por meio da dizimação e da escravização dos Outros e estava baseada em diferenças 
biológicas ou étnicas. Essas crenças ganharam status de teoria em determinado momento e passaram a ser fortemente propagadas e defendidas em diferentes lugares, inclusive nas antigas colônias: “[...] milhões de páginas em tratados, ensaios, monografias, teses, etc., foram escritas para sustentar o insustentável: o racismo como uma prática necessária e justificável” (MUNANGA, 2005, p. 42).

Por outro lado, é perceptível que as práticas racistas vêm sendo modificadas em alguns aspectos, ganhando contornos que diferem do antigo racismo materializado na escravização, nas manifestações públicas depreciativas em larga escala, entre outras formas que eram socialmente aceitas. E embora algumas dessas práticas antigas ainda possam ocorrer de forma pontual em alguns espaços, o novo racismo tenta se apresentar como benevolente.

Diferenciando-se um pouco do sentido da ideologia da supremacia branca original, no novo racismo, as minorias não são mais biologicamente inferiores. Elas são vistas como culturalmente diferentes e essas diferenças representam, em muitos aspectos, deficiências em relação ao padrão hegemônico (VAN DIJK, 2000). Essa postura poderia ser considerada positiva caso o ser diferente não significasse ter características físicas ou culturais inferiorizadas e ressaltadas como estratégia de manutenção das estruturas sociais desiguais.

Outro aspecto do racismo contemporâneo é ainda mais preponderante para a sua perpetuação: a negação. E graças a essa atitude socialmente compartilhada por aqui e em diversas partes do mundo, pode haver a falsa sensação de que esse problema não existe.

Aliás, essa naturalização, no caso brasileiro, está diretamente relacionada à criação do mito da democracia racial, que conseguiu construir a crença de que o Brasil representava um caso bem sucedido de democracia racial. A solidificação desse mito, segundo Fernandes (2015), logrou êxito, principalmente, por ter sido orquestrada pela elite simbólica ${ }^{4}$ brasileira.

Essa lenda alcançou tamanho respaldo que a Unesco, em 1951, promoveu um estudo baseado na hipótese de que o Brasil representava um caso neutro de manifestação de preconceito racial com o objetivo de apresentar nosso "modelo" ao mundo como referência à pacificação de problemas semelhantes vivenciados por outras nações. E foi justamente a partir dos resultados dessa pesquisa que o mito da democracia étnica passou a ser combatido com mais ênfase por aqui, pois os pesquisadores constataram que não éramos [e ainda não somos] essa espécie de oásis de convivência harmônica entre os diferentes (FERNANDES, 2015).

\footnotetext{
${ }^{4}$ Esse grupo é composto por políticos, jornalistas, juízes, professores, empresários, cientistas, entre outros, que tem acesso preferencial e o controle sobre o discurso público. Essa elite, segundo van Dijk (2016b), além da base simbólica costuma também, concomitantemente, controlar a base material do poder social.
} 
Produto de práticas sociais, o racismo passou a ser empregado como instrumento ideológico que vem dando legitimação à dominação dos grupos hegemônicos, especialmente no Brasil onde minorias foram dizimadas e colocadas à margem, caso também das comunidades remanescentes de quilombos. Essas etnias, em função de ter sua história marcada pelos males do período escravocrata, ainda vivenciam as práticas segregacionistas que lhes renegam acesso a direitos sociais e simbólicos. Na próxima seção, discutiremos esse contexto, abordando de forma especial um dos direitos que estão sendo negados a essa minoria: o reconhecimento de seu território.

\section{A LUTA PELO TERRITório}

Os fenômenos sociais e históricos que possibilitaram a existência de comunidades remanescentes de quilombos no Brasil têm relação direta com o período escravocrata. Dessa forma, a luta desse grupo étnico, que se perpetua desde a chegada dos primeiros escravizados ao país, integra-se à complexa forma como esta nação vem lidando com a questão racial.

O termo quilombo era até pouco tempo algo pertinente aos estudos e pesquisas sobre a história do Brasil. Em parte, considerável das narrativas produzidas, esse espaço e a população vinculada ao mesmo foram retratados de forma estigmatizada, reduzindo seu amplo significado político, cultural e social ao campo semântico da fuga e da rebelião. Especialmente a partir da década de 1960, coube à historiografia, junto com uma série de estudos antropológicos mais recentes, promover uma releitura sobre a história da escravização, o que também proporcionou nova perspectiva sobre o sentido de quilombo (OLIVEIRA, 2016).

Para Arruti (1997), é fundamental que se desloque a tentativa de se compreender as comunidades quilombolas para o campo étnico, problematizando sua existência a partir de um processo de autoconstituição como grupos sociais e culturais diferenciados. Têm-se, então, as identidades das comunidades remanescentes de quilombos percebidas a partir da sua constituição enquanto grupo étnico, implicando uma ressignificação importante, com desdobramentos, inclusive, nas políticas públicas de titulação dos territórios. ${ }^{5}$

\footnotetext{
${ }^{5}$ O Estado passou a considerar essa nova perspectiva para quilombo, especialmente a partir do Decreto n. 4.887/2003 da Presidência da República, que assim o conceitua: "Art. $2^{\circ}$ Consideram-se remanescentes das comunidades dos quilombos, para os fins deste Decreto, os grupos étnico-raciais, segundo critérios de auto-atribuição, com trajetória histórica própria, dotados de relações territoriais específicas, com presunção de ancestralidade negra relacionada com a resistência à opressão histórica sofrida".
} 
E por falar em política pública, é fato que o Estado brasileiro demorou a reconhecer formalmente as comunidades quilombolas. Porém, a inserção do Art. $68^{6}$ no Ato das Disposições Constitucionais Transitórias (ADCT) da Constituição Federal (CF) e a edição de outros instrumentos normativos foram insuficientes à consolidação desse direito. No caso específico do estado do Espírito Santo sobre o qual o jornal A Gazeta lança o olhar na reportagem, por exemplo, as estatísticas são categóricas: nenhum território foi titulado até o fechamento deste artigo.

Todavia, o descaso estatal não é o único embate suportado por essa minoria. A disputa no campo discursivo também impõe uma série de obstáculos a essas comunidades, que na luta pela titulação do território vivenciam constantes conflitos no processo de ressignificação de sua própria existência em sentido cultural, econômico, social, político etc. (OLIVEIRA, 2011).

O que não causa surpresa em meio a esses embates é o fato de que, mesmo sem os direitos dos povos quilombolas terem sido concretizados, apenas a expectativa de modificação na estrutura social e fundiária a partir das propostas de regularização dos territórios fora suficiente à emergência de questionamentos jurídicos e étnicos, materializados pela reação dos grupos ideologicamente contrários a essa política afirmativa.

Em meio a essa reação, a imprensa produziu diversos textos em torno da temática, entre os quais a reportagem selecionada para a produção deste artigo. Para entender o papel desse conteúdo na relação de disputa de poder na sociedade, antes de efetivarmos a análise propriamente dita, realizaremos discussões sobre a imprensa, o poder e a produção de discurso.

\section{COMUNICAÇÃO E PODER: O DISCURSO "NA" / "DA" IMPRENSA}

Mesmo que a relevância [e o poder] da imprensa venha sendo contestada contemporaneamente em função do crescimento do conteúdo consumido nas mídias sociais digitais não noticiosas, o jornalismo ainda mantém a sua força simbólica. Isso pode ser constatado ao se observar o papel que os veículos tradicionais ocupam na "checagem" das fake news. Assim, mesmo que o volume de desconfiança em relação à grande imprensa esteja aumentando, pesquisas ainda demonstram que para a maioria "[...] uma informação é verdadeira quando todos os meios de comunicação afirmam que ela o é; se o rádio, o jornal, a televisão e a internet divulgam a mesma coisa, nós aceitamos porque, intuitivamente, a repetição serve como prova de veracidade" (MORAES, 2013, p. 60). Mais do que isso, a relação entre o poder e a comunicação é de dependência, estando a mídia no centro dessa dinâmica social:

\footnotetext{
6 “Art. 68. Aos remanescentes das comunidades dos quilombos que estejam ocupando suas terras é reconhecida a propriedade definitiva, devendo o Estado emitir-lhes os títulos respectivos” (BRASIL, Constituição Federal, 1988). 
O poder é mais do que comunicação e a comunicação é mais do que poder. Mas o poder depende do controle da comunicação, assim como o contrapoder depende do rompimento desse controle. E a comunicação de massa, a comunicação que potencialmente atinge a sociedade como um todo, é moldada e administrada por relações de poder, tem raízes nos negócios da mídia e nas políticas de Estado. O poder da comunicação está no âmago da estrutura e da dinâmica da sociedade (CASTELLS, 2015, p. 21).

De acordo com van Dijk (2000), bem como para estudiosos do próprio campo do jornalismo (TRAQUINA, 2005), não há mais necessidade de se discutir o poder da imprensa. Para o linguista, o discurso da imprensa está entre os que mais exercem influência na vida das pessoas.

Os discursos [re]produzidos pela imprensa são portadores de imaginários sociais que têm influência sobre as opiniões do público. Conforme ilustra Charaudeau (2006, p. 285), a imprensa consegue inserir o cidadão em um mundo em que não é possível se distinguir a realidade da ficção, pois o campo jornalístico é capaz de apresentar "[...] uma espécie de verdade verossímil, que faz fundirem-se os dados da ficção na ilusão do autêntico por meio de uma narrativa que constrói seu próprio ideal, fazendo comércio de nossos imaginários".

Esse aspecto se torna ainda mais relevante para a análise que se propõe neste artigo quando pensamos no papel da imprensa no processo de construção e disseminação de modelos mentais racistas. O protagonismo da mídia fica mais evidente quando constatamos que "[...] o discurso da mídia é a principal fonte de conhecimento, atitudes e ideologias das pessoas, tanto das elites quanto dos cidadãos comuns [...]"7 (VAN DIJK, 2000, p. 36, tradução nossa).

E o jornal de onde foi extraído o objeto desta análise está inserido nessa dinâmica comunicacional, pois se trata de um dos maiores e mais influentes jornais do estado e que integra também a maior e mais influente rede de comunicação do Espírito Santo (MARTINUZZO, 2008).

Assim, a partir de toda discussão conceitual realizada até o momento, realizaremos na próxima seção a análise do discurso do jornal A Gazeta, conforme reportagem selecionada.

\section{ANÁliSE DA REPORTAGEM}

É inerente a uma análise do discurso que se pretenda mais completa examinar não só as estruturas discursivas, mas também as estruturas de contexto. Partindo desse entendimento, apresentamos um quadro com os principais pontos do contexto identificados a partir da reportagem:

\footnotetext{
7 “[...] media discourse is the main source of people's knowledge, attitudes and ideologies, both of other elites and of ordinary citizens $[\ldots]$ ".
} 
Quadro 1: Categorias de Contexto - produzido pelos autores com base em van Dijk (2017b)

\begin{tabular}{|c|c|}
\hline Cenário & $\begin{array}{l}\text { - Linha editorial do jornal direcionada às classes A, B e C; } \\
\text { - Ano de 2007, início do segundo mandato do presidente Lula; } \\
\text { - Estão em vigor uma série de ações de combate às desigualdades } \\
\text { raciais que provocam reações em setores conservadores da sociedade } \\
\text { brasileira (direita, ruralistas, evangélicos etc.); } \\
\text { - No Espírito Santo, início das notificações feitas pelo Incra aos } \\
\text { ocupantes das áreas delimitadas como territórios quilombolas; } \\
\text { - Mobilização de fazendeiros contrários à política, criando, inclusive, } \\
\text { uma organização para se contrapor à política de titulação denominada } \\
\text { Movimento Paz no Campo (MPC); } \\
\text { - Publicação da primeira reportagem sobre a questão no jornal A } \\
\text { Gazeta; } \\
\text { - Repercussão da publicação nos espaços em que o jornal } \\
\text { circula/atinge. }\end{array}$ \\
\hline Participantes & $\begin{array}{l}\text { - A jornalista que assina o texto; } \\
\text { - Os proprietários rurais e quilombolas (como grupos); } \\
\text { - Atores contrários ouvidos: Edivaldo Permanhane, líder do MPC / } \\
\text { Elieser Nardoto, historiador contratado para assessorar os } \\
\text { proprietários rurais contrários à titulação / Robson Almeida Barbosa, } \\
\text { produtor rural e Augusto Piu, trabalhador rural; } \\
\text { - Atores favoráveis ouvidos: Incra (via assessoria de imprensa) / } \\
\text { Dona Miúda (moradora de uma comunidade quilombola); }\end{array}$ \\
\hline Eu-mesmo & $\begin{array}{l}\text { Jornalista: controla todo o discurso, selecionando as fontes ouvidas e } \\
\text { definindo os espaços ocupados por cada ator. } \\
\text { Diagramador/editor: edita/diagrama o texto e dá ênfase aos tópicos e } \\
\text { temas empregando elementos multimodais. }\end{array}$ \\
\hline Ações e eventos comunicativos & $\begin{array}{l}\text { - Notificação de proprietários rurais; } \\
\text { - Mobilização de atores políticos e sociais visando a intervir no } \\
\text { processo; } \\
\text { - Publicação da reportagem; } \\
\text { - Apresentações nesse texto de versões/interpretações sobre o } \\
\text { processo de titulação de territórios quilombolas; }\end{array}$ \\
\hline Cognição (pessoal-social) & $\begin{array}{l}\text { - Intenção: Aprofundar a cobertura sobre a titulação de territórios } \\
\text { quilombolas, considerando que outros gêneros textuais menos } \\
\text { explicativos já vinham noticiando sobre a questão; } \\
\text { - Conhecimento (base comum): Direito à propriedade privada, } \\
\text { quilombos como estruturas sociais do passado ligadas ao processo de } \\
\text { escravização; } \\
\text { - Atitudes e ideologias: racismo; negação das desigualdades sociais } \\
\text { em termos de raça e etnia; oposição às políticas públicas de inclusão } \\
\text { racial; proteção à propriedade privada em detrimento do interesse } \\
\text { público (ideologia capitalista). }\end{array}$ \\
\hline
\end{tabular}

Passamos, na sequência, a abordar as estruturas do discurso a partir da Semântica Global. A observação inicial dessas partes principais do objeto demostra que o discurso da reportagem dá ênfase ao caráter conflitivo do processo de titulação dos territórios quilombolas e atribui aos fazendeiros o papel de protagonistas e vítimas do processo. O outro lado interessado na questão - os quilombolas e o governo Federal - são colocados nessas macroestruturas em posições negativas, por ameaçarem a tranquilidade dos proprietários rurais.

Essas constatações podem ser identificadas já a partir do título que destaca o aspecto conflitivo por meio do emprego do verbo "lutar": "Proprietários lutam por terras em São Mateus" (A GAZETA, 2007, p. 3, conforme Anexo 1). Além do termo "proprietários" como sujeitos agentes, o sentido determinado é o de garantia de posse do bem, como aquele que tem a propriedade de alguma coisa, no caso, as terras. Nesse mesmo sentido, a metáfora do verbo "lutar" exigiria um 
objeto pessoa, já que não aciona um sentido de esforço pela terra, mas de enfrentamento, de embate com o outro.

O chapéu, termo utilizado no jornalismo para indicar o que está posicionado acima do título principal e é empregado para evidenciar o assunto de que trata o texto, por sua vez, apresenta os fazendeiros em posição ativa em defesa da propriedade privada. Além dessa posição proativa, o emprego de uma metáfora discursiva com fins persuasivos por meio do uso do vocábulo peregrinação para descrever essa ação dramatiza o processo e relaciona, devido à carga semântica dessa palavra, a ação dos grupos contrários à titulação a um espectro de cunho religioso, como se as iniciativas tomadas por eles contra os processos de titulação representassem um sacrifício por algo justo: "Situação: produtores iniciaram uma peregrinação aos gabinetes de políticos" (A GAZETA, 2007, p. 3). Além disso, a escolha lexical de "produtores" reforça uma apresentação positiva do grupo, já que eles não são apenas proprietários do bem, da terra, mas produzem e geram empregos. Junto ao uso de "peregrinação", como expomos acima, a construção discursiva do enunciado reforça o valor dos argumentos favoráveis ao grupo de elite.

A linha fina, texto posto após o título para "abrir" a reportagem, por meio do emprego da sintaxe oracional, volta a dar destaque aos fazendeiros, colocando-os, dessa vez, em posição de vítimas: "Eles temem que suas terras sejam desapropriadas pelo governo federal para os quilombolas" (A GAZETA, 2007, p. 3). Além disso, o verbo "temer" reforça o caráter de medo e injustiça por pertencerem a um grupo que traz recursos para a sociedade e que podem perder suas terras, marcadamente pertencentes a eles, pelo reforço do pronome de posse "sua".

Assim, esses efeitos são acionados com o uso do período composto por subordinação no qual a oração principal tem como sujeito o pronome pessoal "eles", que substitui o substantivo ("proprietários") anteriormente apresentado no título principal. Percebemos novamente que a jornalista desloca esses atores sociais para uma posição privilegiada e proativa na sentença. Além disso, nessa oração principal a opção pelo verbo "temer" dá ênfase a uma suposta situação de insegurança vivenciada pelos fazendeiros. O outro componente desse período composto - a oração subordinada substantiva objetiva direta - por ter a função de completar o sentido do verbo da oração principal direciona aos atores sociais favoráveis à titulação (governo Federal e quilombolas) a carga semântica negativa do verbo "temer" nesse contexto. Essas macroposições semânticas inferidas a partir da observação do título, do chapéu e da linha fina são reforçadas e tornam-se recorrentes ao longo do texto principal da reportagem.

O exame da apresentação e da descrição dos atores/interesses participantes do ato comunicativo, por exemplo, demonstra que a jornalista construiu uma polarização entre os grupos 
favoráveis e contrários à titulação dos territórios, delineando o emprego do quadrado ideológico na construção do discurso.

Para se referir ou qualificar os fazendeiros, o jornal utiliza termos como proprietários, produtores e trabalhador rural. Outro participante contrário à titulação a quem o jornal também ouve e dá voz por meio de um discurso direito é qualificado como historiador, um típico integrante da elite simbólica que teve acesso privilegiado a esse discurso público sobretudo pela autoridade que lhe é atribuída pelo jornal para falar sobre o assunto. A inserção de uma fonte com esse tipo de atributo (título de especialista no assunto) ajuda a dar credibilidade e a reforçar o peso dos argumentos contrários à titulação.

As fazendas ocupadas por esse grupo, por sua vez, são qualificadas no discurso como terras, propriedades e áreas; e descritas como produtivas e que geram riqueza e empregos: “Além disso, são áreas produtivas [...]", “A agricultura mateense responde por 35\% do PIB”, "Várias dessas propriedades geram centenas de empregos" e "[...] terra de produtor que está produzindo" (A GAZETA, 2007, p. 3).

Os atores sobre os quais o direito previsto no art. 68 incide - os quilombolas - são qualificados no discurso somente como quilombolas, sem uso de nenhum outro vocábulo para referenciar esses atores. O Incra, outro participante favorável à titulação, é qualificado como governo Federal ou somente pela sigla oficial do órgão. Contudo, o órgão recebe uma acusação na construção do discurso interessante de ser observada: "O movimento acusa o Incra de não ter sido transparente no processo e de querer criar a segregação racial” (A GAZETA, 2007, p. 3). Nesse trecho, fica evidente, dentro da estratégia do quadrado ideológico, que o discurso ao tempo que não enfatiza os aspectos negativos do grupo contrário à titulação - por exemplo, uma atitude racista enfatiza aspectos negativos do outro lado, a segregação racial. Um caso típico de negação do racismo a partir da transferência da culpa ao outro lado.

Observando essas qualificações e descrições podemos inferir que o discurso veiculado nessa reportagem evidencia uma polarização valorativa no nível global do discurso. De um lado enfatiza o produtivo como polo positivo, que representa as terras dos fazendeiros - "[...] são áreas produtivas [...] A agricultura mateense responde por 35\% do PIB [...] Várias dessas propriedades geram centenas de empregos" (A GAZETA, 2007, p. 3).

E do outro lado, enfatiza o improdutivo como polo negativo ao supor prejuízos se a titulação de territórios quilombolas de fato ocorrer - medo: "Temendo terem suas terras desapropriadas" (A GAZETA, p. 3, 27 maio 2007); segregação racial: “O movimento acusa o Incra de [...] querer criar a segregação racial" e "O Brasil é um só. É um absurdo construir uma comunidade quilombola, separando branco de negro" (A GAZETA, p. 3, 27 maio 2007); 
desemprego e prejuízo econômico: "Imagina o que serão destes trabalhadores? Não serão só os proprietários que serão atingidos. Todo o município será atingido" (A GAZETA, p. 3, 27 maio 2007); e violência: “Como eu, muitos proprietários (não) estão dispostos a sair da sua terra nem mortos" (A GAZETA, p. 3, 27 maio 2007).

Ademais, a partir da forma como os tópicos e os temas são organizados ao longo do texto, observando os trechos citados acima, podemos perceber que o discurso presente nessa reportagem enquadra o direito à titulação dos territórios quilombolas como algo negativo e que causará prejuízo econômico e social à sociedade.

Assim, nos termos construídos nesse discurso prevalece a ideologia capitalista na forma e nas atitudes diante de situações que ameaçam a propriedade privada. Essa ideologia pode ser identificada por meio dos modelos mentais situacionais que aparecem no texto.

E por fim, embora exista uma diversidade de outros elementos a serem ainda observados no texto, na primeira oração do corpo do texto da reportagem a jornalista deixa claro a partir de qual modelo mental sobre a titulação de territórios quilombolas a reportagem será construída: “A polêmica da questão quilombola está definitivamente instalada em São Mateus" (A GAZETA, p. 3, 27 maio 2007, grifo nosso).

A repórter, a partir dessa afirmação inicial, por meio do uso do modalizador persuasivo "definitivamente", procura reforçar sua avaliação do valor de verdade da proposição, qual seja, de que o processo de titulação pode ser definido como uma polêmica e não como um direito das famílias quilombolas previsto na CF. Por meio do uso de uma sentença diferente, a jornalista poderia ter comunicado o mesmo fato, como por exemplo: "As ações visando o cumprimento do Art. 68 da CF federal têm gerado reações contrárias por parte dos fazendeiros de São Mateus”. Contudo, a diferença entre as duas formas (a original e a alternativa) se dá justamente em função do modelo mental a partir do qual as orações foram construídas. É nesse sentido que entendemos esse modalizador como estratégia de persuasão e argumentação, já que sua função é intensificar um fato que já é do conhecimento geral para convencer o outro da veracidade do que está sendo dito. Fica evidente que o uso desse modalizador pretende adquirir uma verdade incontestável no discurso jornalístico, de modo a convencer o outro e, ao mesmo tempo, expressar o ponto de vista assumido na reportagem.

\section{CONSIDERAÇÕES FINAIS}


O objetivo deste artigo foi o de, por meio da análise de estruturas discursivas, identificar se o discurso veiculado no objeto de pesquisa reproduz a desigualdade no acesso a bens materiais e simbólicos e o abuso de poder materializado em práticas racistas.

Nessa esteira, com base na análise realizada ficou evidente o tratamento diferenciado dado pelo discurso da reportagem aos fazendeiros em detrimento dos integrantes das comunidades quilombolas. Além de ter privilegiado os primeiros em termos de ocupação de espaços e de seleção de fontes, o texto também empregou a estratégia do quadrado ideológico:

- enfatizou os aspectos positivos do grupo contrário à titulação (são proprietários das áreas, produtores rurais, geram empregos etc.);

- enfatizou os aspectos negativos da titulação (poderia causar desemprego, prejuízo econômico, segregação racial e até morte), bem como do próprio processo realizado (falta de transparência e legitimidade);

- não enfatizou aspectos positivos dos quilombolas (como direito previsto na Constituição Federal, o papel de produtores rurais que também desempenham, além dos aspectos históricos e culturais fundamentais silenciados); e

- não enfatizou os aspectos negativos dos grupos contrários (como a ideologia racista ainda presente nas atitudes e ideologias dos mesmos).

Identificamos também que a reportagem reproduz a ideologia capitalista por meio dos modelos mentais situacionais que aparecem no texto. Por exemplo, as atitudes da jornalista e dos fazendeiros diante de um direito constitucional que tem por objetivo, entre outras coisas, reparar as desigualdades promovidas por anos de práticas racistas estruturais no Brasil. Tanto a jornalista quanto os proprietários rurais e o historiador privilegiaram em suas falas o "olhar" economicista da questão, ignorando os aspectos sociais, étnicos e raciais.

Além disso, o discurso presente nessa reportagem reproduz a realidade social das comunidades quilombolas que, além de não terem o direito ao território alcançado, sofrem das demais mazelas das desigualdades também vivenciadas pela maioria do povo negro no Brasil. O texto reflete ainda a forma preconceituosa como esse grupo étnico é retratado em outros espaços da sociedade, tendo suas características positivas silenciadas e substituídas por aspectos negativos. Essa atitude socialmente compartilhada ajuda na construção dos modelos mentais que mantêm vivo o racismo.

A exemplo do que estamos adotando como premissa em outros estudos semelhantes já realizados, mais do que apontar por meio da análise das estruturas como o discurso construído pela jornalista foi tendencioso, favorecendo um dos lados envolvidos na polarização apresentada, a missão principal aqui pretendida é demonstrar como os discursos construídos pela imprensa - 
geralmente caracterizados somente como uma cobertura parcial da situação - podem [e devem] ser vistos como práticas racistas. E mais, como simples textos produzidos por meio de práticas diárias e muitas vezes automatizadas são capazes de construir modelos mentais racistas que em muito prejudicam minorias étnico-raciais como as comunidades remanescentes de quilombos.

\section{REFERÊNCIAS BIBLIOGRÁFICAS}

ARRUTI, José Maurício Andion. A emergência dos “remanescentes": notas para diálogo entre indígenas e quilombolas. Revista Mana. Rio de Janeiro, v. 3, n. 2, out. 1997.

BRASIL. Constituição da República Federativa do Brasil. Brasília/DF: Senado Federal, 1988.

BRASIL. Decreto $n^{\circ} 4.887$, de 20 de novembro de 2003. Regulamenta o procedimento para identificação, reconhecimento, delimitação, demarcação e titulação das terras ocupadas por remanescentes das comunidades dos quilombos de que trata o art. 68 do Ato das Disposições Constitucionais Transitórias. Diário Oficial da União, Brasília, DF, 21 nov. 2003.

CASTELLS, Manuel. O poder da comunicação. São Paulo: Paz e Terra, 2015.

CHARAUDEAU, Patrick. Discurso político. São Paulo: Contexto, 2006.

ETHOS. Perfil social, racial e de gênero das 500 maiores empresas do Brasil e suas ações afirmativas. São Paulo: Instituto Ethos e Banco Interamericano de Desenvolvimento, 2016.

FERNANDES, Florestan. O negro no mundo dos brancos. São Paulo: Global, 2015.

IBGE. Pnad. 2017. Disponível em: https://www.ibge.gov.br/estatisticasnovoportal/sociais/educacao.html. Acesso em: 23 maio 2018.

MARQUES DE MELO, José. Jornalismo opinativo: gêneros opinativos no jornalismo brasileiro. 3. ed. ver. e ampl. Campos de Jordão: Editora Mantiqueira, 2003.

MARTINUZZO, José Antônio (org.). Quase 200 anos: a imprensa na história capixaba. Vitória: Departamento de Imprensa Capixaba, 2008.

MORAES, Dênis de (org.). Mídia, poder e contrapoder. São Paulo: Boitempo, 2013.

MUNANGA, Kabengele. Superando o racismo na escola. Brasília: MEC/BID/Unesco, 2005.

OLIVEIRA, Osvaldo Martins. (org.). Direitos quilombolas \& dever de Estado em 25 anos da Constituição Federal de 1988. Rio de Janeiro: Associação Brasileira de Antropologia, 2016.

OLIVEIRA, Osvaldo Martins. Comunidades quilombolas no Estado do Espírito Santo: conflitos sociais, consciência étnica e patrimônio cultural. Revista do Centro de Estudos Rurais (RURIS). Campinas, v. 5, n. 2, 2011. Disponível em:

https://www.ifch.unicamp.br/ojs/index.php/ruris/article/view/1469/986. Acesso em: 20 fev. 2017.

ORGANIZAÇÃO DAS NAÇÕES UNIDAS (ONU). Convenção da Organização das Nações Unidas (ONU/1966) sobre a Eliminação de todas as Formas de Discriminação Racial. Disponível em: https://www.oas.org/dil/port/. Acesso em: 26 maio 2018.

OXFAM BRASIL. A distância que nos une. 2017. Disponível em: https://www.oxfam.org.br/sites/default/files/arquivos/Relatorio_A_distancia_que_nos_une.pdf. Acesso em: 23 maio 2018. 
PACHECO, Sandra. Proprietários lutam por terra em São Mateus. A Gazeta, Vitória, 27 maio 2007. Cidades, p. 3.

TOMAZI, M. M.; CABRAL, A. L. T. Argumentação e estratégias textual discursivas. Language and Law / Linguagem e Direito, v. 4, n. 2, p. 50-71, 2017.

TRAQUINA, Nelson. O estudo do jornalismo no século XX. São Leopoldo: Unisinos, 2005.

VAN DIJK, Tean A. Discurso e contexto: uma abordagem sociocognitiva. Tradução de Rodolfo Ilari. São Paulo: Contexto, $2017 b$.

VAN DIJK, Tean A. Discurso e poder. São Paulo: Contexto, 2017a.

VAN DIJK, Tean A. Discurso-cognição-sociedade: estado atual e perspectivas da abordagem sociocognitiva do discurso. Revista Digital do Programa de Pós-Graduação em Letras da PUCRS (Letrônica). Porto Alegre, v. 9, n. esp. (supl.), s8-s29, 2016b. Disponível em:

https://www.revistaseletrônicas.pucrs.br/ojs/index.php/letronica/. Acesso em: 21 maio 2018.

VAN DIJK, Tean A. Análise crítica do discurso. Tradução de Raquelli Natale, Micheline Mattedi Tomazi e Lúcia Helena Peyronton da Rocha. In: TOMAZI, M. M. et al. (Org.). Estudos discursivos em diferentes perspectivas: mídia, sociedade e direito. São Paulo: Terracota, 2016a. p. 19-42.

VAN DIJK, Tean A. Ideologia. Tradução de Pedro Theobald. Letras de Hoje, Porto Alegre, v. 50, n. esp., p. 53-61, dez. 2015b.

VAN DIJK, Tean A. Discurso das elites e racismo institucional. In: LARA, Glaucia Proença; LIMBERTI, Rita Pacheco (org.). Discurso e (des)igualdade social. São Paulo: Contexto, 2015a.

VAN DIJK, Tean A. Racismo e discurso na América Latina. São Paulo: Contexto, 2008.

VAN DIJK, Tean A. New(s) Racism: A discourse analytical approach. In: COTTLE, Simon (ed.). Ethnic Minorities and the Media. Milton Keynes, UK: Open University Press, 2000. p. 33-49.

VAN DIJK, Tean A. Discourse and Inequality. Lenguas Modernas. (Universidad de Chile) n. 21, p. 19-37, 1994. Disponível em:

https://lenguasmodernas.uchile.cl/index.php/LM/article/view/45582/47644. Acesso em: 7 jul. 2018. 
ANEXO 1 - Reportagem (A GAZETA, 27/05/07, p. 03)

SITUAÇÃO PRODUTORES INICIARAM UMA PEREGRINAÇÃO AOS GABINETES DE POLÍTICOS

\section{Proprietários lutam por terras em São Mateus}

Eles temem que suas terras sejam desapropriadas pelo governo federal para os quilombolas

\begin{tabular}{|c|c|}
\hline $\begin{array}{l}\text { SANDRA PACHECO } \\
\text { spacheco@iredegazeta.com.br }\end{array}$ & $\begin{array}{l}\text { te contra o projeto. } \\
\text { Os produtores iniciaram } \\
\text { uma peregrinação aos gabine- } \\
\text { tes de polítios no Estado e } \\
\text { em Brasilia e com lideranças }\end{array}$ \\
\hline $\begin{array}{l}\text { SÁO MATEUS. A polêmica da } \\
\text { questấa quilombola está de- } \\
\text { finitivamente instada }\end{array}$ & nos municípios do Norte. \\
\hline $\begin{array}{l}\text { finitivamente instalada em } \\
\text { São Mateus. Temendo terem }\end{array}$ & nização e e Reforma Agrá- \\
\hline
\end{tabular}

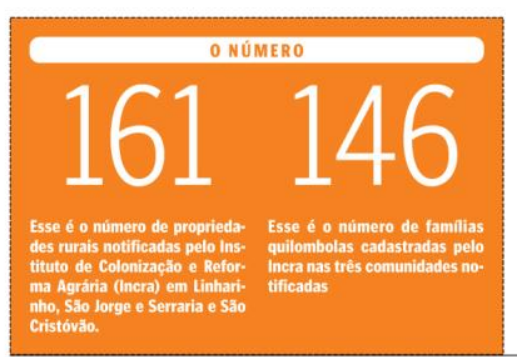
ciaram a criação do Movi- prietários estão dispostos a sair da sua terra nem mortos",disse Edivaldo Permanhane, um dos lideres do MPR. O movimento
acusa o Incra de não ter sido transparente no proceso e de querer criar a segregação racial.

"O Brasil é um só. É um absurdo construir uma comtrando branco de negro. Além disso, são áreas produtivas e, na sua maioria, de pequeno porte. A agricultura mateense responde po $35 \%$ do 11 , destaca o his que está assessorando os proprietários.

"Várias dessas propriedades geram centenas de empregos. Imagina o que serão destes trabalhadores? Nào serâo só os proprietários que nicípio será atingido", disse nicípio será atingido", diss pelo governo federal para a $\mathrm{mar}, \mathrm{em}$ uma audiênci quilombolas no Norte do Es- Mateus este ano, que as ado, os proprietários anun- desapropriações seriam LEl. Já o Incra ressalta que o já o Incra ressalta que do e em dinheiro, e não em dentro da lei, e que nad Titulo da Divida Agrária tem sido feito escondido. desapropriaços para re de que o clima de pavor forma agrária. dem sido causadopelos Mas os produtores dizem proprios proprietários. que não estão interessados "Não é um processo rápiem se desfazer das suas do. Depois das notificapropriedades e que pre- çōes e da defesa, aind tendem lutar para evitar a vem a fase judicial, decla"Como eu, muitos pro-
Assessoria.

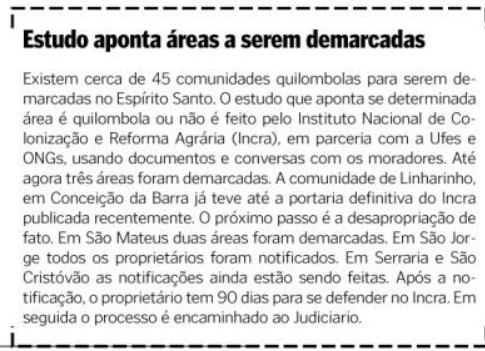

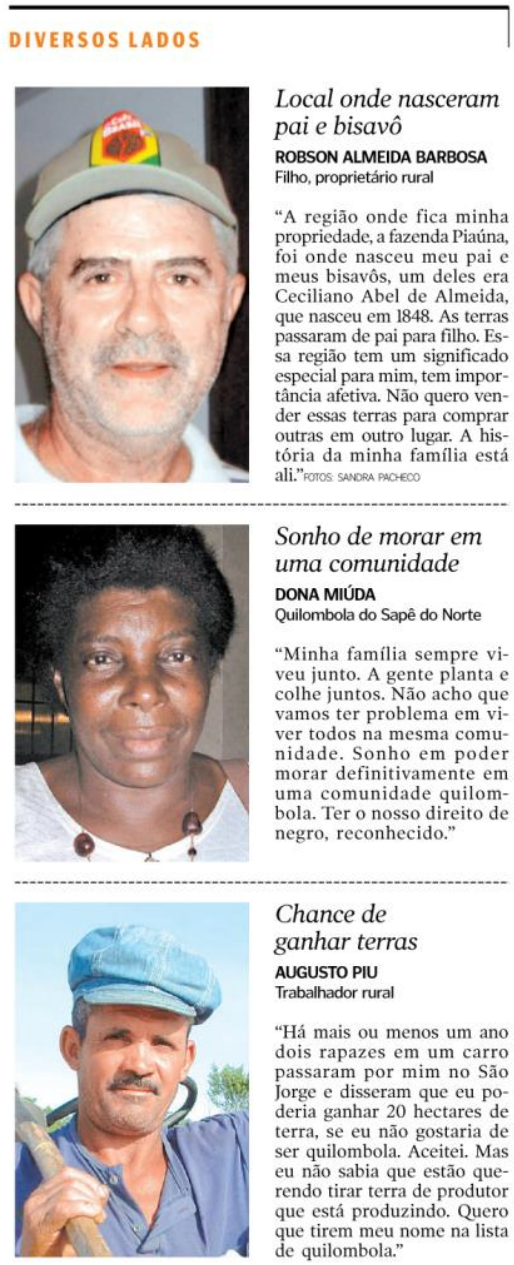

